\title{
Advanced multicentric lymphoma in a Belgian Draft Horse mare
}

\author{
Esther W. Siegers' ${ }^{1}$ Marianne M. Sloet van Oldruitenborgh-Oosterbaan' ${ }^{7}$ Linda van den Wollenberg ${ }^{2}$, Sabrina Jansen ${ }^{3}$, Erik Teske ${ }^{4}$, \\ Nynke Ankringa ${ }^{5}$, Antoon-Jan M. van den Belt ${ }^{6}$ and Cornélie M. Westermann ${ }^{7}$ \\ 1 Department of Equine Sciences, Faculty of Veterinary Medicine, Utrecht University, Utrecht, The Netherlands \\ 2 Animal Health Service, Deventer, The Netherlands \\ 3 Veterinary Clinic Steenbergen, The Netherlands \\ ${ }^{4}$ Department of Clinical Sciences of Companion Animal - Internal Medicine, Faculty of Veterinary Medicine, Utrecht University, Utrecht, The Netherlands \\ ${ }^{5}$ Department of Pathobiology, Faculty of Veterinary Medicine, Utrecht University, Utrecht, The Netherlands \\ ${ }^{6}$ Department of Diagnostic Imaging, Faculty of Veterinary Medicine, Utrecht University, Utrecht, The Netherlands
}

\begin{abstract}
Summary: A 15-year old draft horse mare was presented to the University Clinic for evaluation of lethargy, anorexia, ptyalism, weight loss and ventral oedema. Clinical examination and rectal palpation revealed generalised lymphadenopathy and numerous firm subcutaneous and abdominal masses of various sizes. Transcutaneous ultrasonography revealed significant bilateral pleural fluid accumulation and a single hypoechoic structure in the abdomen lateral to the liver. Blood analysis showed several abnormalities including a marked leucocytosis with an increased number of segmented neutrophils, atypical lymphocytes and monocytosis, suggestive of leukaemic lymphoma. A significant hyperproteinaemia with a hypoalbuminemia and a monoclonal gammopathy was identified. At necropsy myriad masses presented through the whole body. Histology confirmed the suspicion of lymphoma, which was classified as a T-cell rich B-cell multicentric lymphoma. This article describes the clinical and pathologic findings of this case of leukaemic lymphoma.
\end{abstract}

Keywords: multicentric, lymphoma, horse, neoplasia, leukaemia, monoclonal gammopathy, oncology

Citation: Siegers E. W., Sloet van Oldruitenborgh-Oosterbaan M. M., van den Wollenberg L., Jansen S., Teske E., Ankringa N., van den Belt A.-J. M., Westermann C. M. (2017) Advanced multicentric lymphoma in a Belgian Draft Horse mare. Pferdeheilkunde 33, 30-36; DOI 10.21836/PEM20170104

Correspondence: Esther W. Siegers, Department of Equine Sciences, Utrecht University, Yalelaan 112, 3584 CM Utrecht, The Netherlands; E-mail: e.w.siegers@uu.nl

\section{Introduction}

Lymphoma is the most common malignant hematopoietic neoplasm in the horse (Muñoz et al. 2009, Janvier et al. 2016, Ness 2016), with a reported incidence of between $1 \%$ and $3 \%$ of all equine tumours (Janvier et al. 2016, Taintor and Schleis 2011). Equine lymphoma arises from lymphoid tissue and is conventionally categorized according to the distribution of tumour lesions as alimentary, cutaneous, mediastinal or multicentric (Schwarz et al. 2012, Ness 2016, Taintor and Schleis 2011).

Although lymphoma may develop at any age most cases are reported in horses 4 to 10 years of age (Muñoz et al. 2009, Taintor and Schleis 2011). The clinical signs are often nonspecific and depend upon the type of tumour and the affected organ(s) (Janvier et al. 2016, Ness 2016). Paraneoplastic syndromes are often the earliest detectable evidence of lymphoma and may include generalised pruritus, undulant pyrexia, cachexia, hypercalcemia and erythrocytosis (Axiak and Johnson 2011, Taintor and Schleis 2011). The total white blood cell count (WBC) is seldom diagnostically helpful since most cases of equine lymphoma are non-leukaemic (Ness 2016). However, leukaemia is occasionally reported in advanced cases. (Muñoz et al. 2009, Ness 2016). Leukaemia may be primary when the neoplasm originates in the bone marrow and neoplastic cells are released into the peripheral circulation. Secondary leukaemia occurs when lymphoma has metastasized to the bone marrow producing a myelophthisic state (Cian et al. 2013, Ness 2016, Taintor and Schleis 2011 ). Leukaemia can be classified by the cell of origin as myeloproliferative or lymphoproliferative, and by maturation stage as acute (blast cells in the circulation) or chronic (mature differentiated cells in the circulation). The presence of neoplastic cells in the circulation can be further differentiated into leukaemic, subleukaemic and aleukaemic forms (Muñoz et al. 2009, Schwarz et al. 2012).

This paper provides an extensive description of the clinical investigation and post mortem examination of an advanced case of multicentric leukaemic lymphoma in a Belgian draft horse.

\section{History}

A 15-year-old Belgian draft horse mare was referred to the University Equine Clinic with progressive signs of lethargy, anorexia, ptyalism, weight loss and ventral oedema over a period of approximately two months. Shortly before referral a blood sample had revealed a marked leukocytosis $\left(49.9 \times 10^{9} / \mathrm{L}\right.$; reference range $\left.5.0-10.0 \times 10^{9} / \mathrm{L}\right)$ with a high monocyte count $\left(17.5 \times 10^{9} / \mathrm{L}\right.$; reference range $\left.0.0-0.4 \times 10^{9} / \mathrm{L}\right)$, and a hyperproteinemia $(117 \mathrm{~g} / \mathrm{L}$; reference range $59-80 \mathrm{~g} / \mathrm{L})$ with a monoclonal gammopathy $(65 \mathrm{~g} / \mathrm{L}$; reference range $6-19 \mathrm{~g} / \mathrm{L})$ (Table 1). The horse was treated by the referring veterinarian at the time with trimethoprim-sulfadiazine (5/25 mg/kg q24h), meloxicam (0.4 mg/kg q24h), methylprednisolone $(0.02 \mathrm{mg} / \mathrm{kg}$ once only) and dexamethasone $(0.006 \mathrm{mg} / \mathrm{kg}$ once only) without significant clinical improvement. 


\section{Clinical examination}

On presentation (shortly after transportation) the mare was excited, sweating and showed severe ptyalism. Body condition was poor (body condition score 2/9; Henneke et al. 1983). The hair coat was long and dull (Figure 1). Respiratory rate (20 breaths/minute), heart rate $(80 \mathrm{bpm})$ and body temperature $\left(38.5^{\circ} \mathrm{C}\right)$ were all elevated. The horse was slightly dehydrated with increased capillary refill time $(3 \mathrm{sec})$, reddened mucous membranes and cold extremities. The nostrils, lips, ventral chest and abdomen showed marked oedema (Figure 1). The mucous membranes of the mouth showed several roughly spherical nodules $1-2 \mathrm{~cm}$ in diameter. The conjunctivae were oedematous and a purulent exudate was present bilaterally. Mucous membranes of the nostrils and the vagina showed marked crusting. Non-painful lymphadenopathy was present in the sub-mandibular, superficial cervical, axillary and superficial inguinal lymph nodes. Additionally, several subcutaneous masses were identified.

On auscultation of the thorax increased broncho-vesicular sounds were detected over the dorsal lung field, whilst ventrally lung sounds were decreased to absent. Thoracic percussion revealed a dull percussion sound ventral to a horizontal line at the level of the shoulder joint.

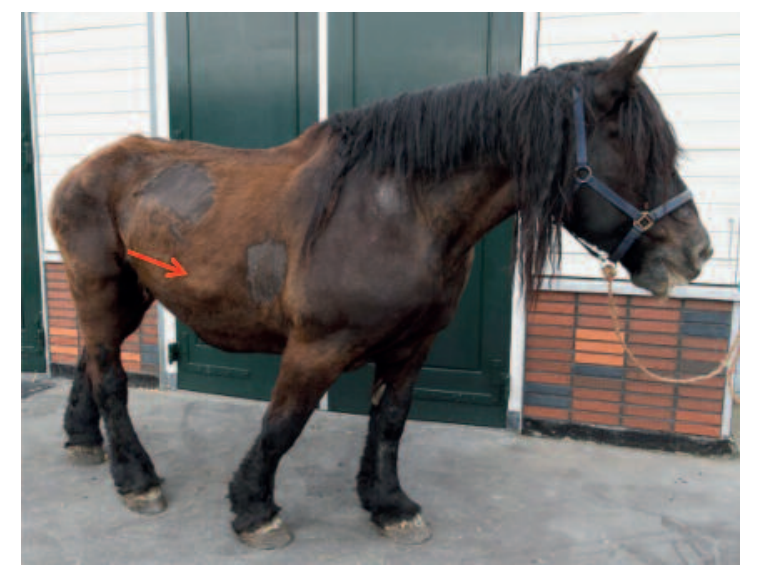

Fig. 1 A 15-year-old Belgian draft horse mare with lymphoma in a very poor body condition, showing a long uneven and dull hair coat, oedema of the nostrils and lips, ptyalism, ventral oedema and a mass (arrow) on the lateral thoracic wall.
Rectal palpation revealed many ovoid firm masses with a diameter between $3-8 \mathrm{~cm}$ within the mesocolon, the cranial mesentery and on the abdominal wall. No abnormalities of the small intestines, colon, spleen and left kidney were detected.

Based on the history and clinical examination neoplastic disease was strongly suspected. Further diagnostic procedures, including thoracic radiography, ultrasonography of thorax and abdomen, blood analysis and thoracocentesis were performed. A fine needle aspirate (FNA) biopsy was collected from a swollen cervical lymph node.

\section{Diagnostic imaging}

Radiography of the thorax identified fluid accumulation in the ventral thoracic cavity. The dorsal lung field showed no abnormalities (Figure 2). Ultrasonography of the thorax revealed hypoechoic fluid accumulation in the ventral thoracic cavity bilaterally up to the level of the shoulder joint (Figure 3). Ultrasonography of the abdomen revealed normal spleen, liver and kidney, however a single large hypoechoic intraabdominal mass $(7 \times 11 \mathrm{~cm})$ could be visualized between the liver and the abdominal wall. No increased volume of abdominal fluid was identified on ultrasound.

\section{Laboratory examinations}

\section{Blood analysis}

A venous blood gas analysis and electrolyte assay showed no abnormalities apart from increased plasma lactate concentration $(3.0 \mathrm{mmol} / \mathrm{L}$; reference range $0.7-1.2 \mathrm{mmol} / \mathrm{L}$ ) (Table 1). Significant hyperproteinaemia $(103 \mathrm{~g} / \mathrm{L}$; reference range $52-79 \mathrm{~g} / \mathrm{L})$ with hypoalbuminemia $(21 \mathrm{~g} / \mathrm{L}$; reference range $26-37 \mathrm{~g} / \mathrm{L})$ and a monoclonal gammopathy $(58 \mathrm{~g} / \mathrm{L}$; reference range $6-19 \mathrm{~g} / \mathrm{L}$ ), were broadly similar to the findings in the blood sample obtained before referral. A leucocytosis $\left(24.8 \times 10^{9} / \mathrm{L}\right.$; reference range $\left.4.7-10.0 \times 10^{9} / \mathrm{L}\right)$ due to increased numbers of segmented neutrophils $\left(13.6 \times 10^{9} / \mathrm{L}\right.$; reference range $\left.2.3-6.5 \times 10^{9} / \mathrm{L}\right)$, lymphocytes $\left(8.9 \times 10^{9} / \mathrm{L}\right.$; reference range $\left.1.1-5.1 \times 10^{9} / \mathrm{L}\right)$ and monocytes $\left(2.2 \times 10^{9} / \mathrm{L}\right.$; reference range $\left.0.5-0.5 \times 10^{9} / \mathrm{L}\right)$ was repor-

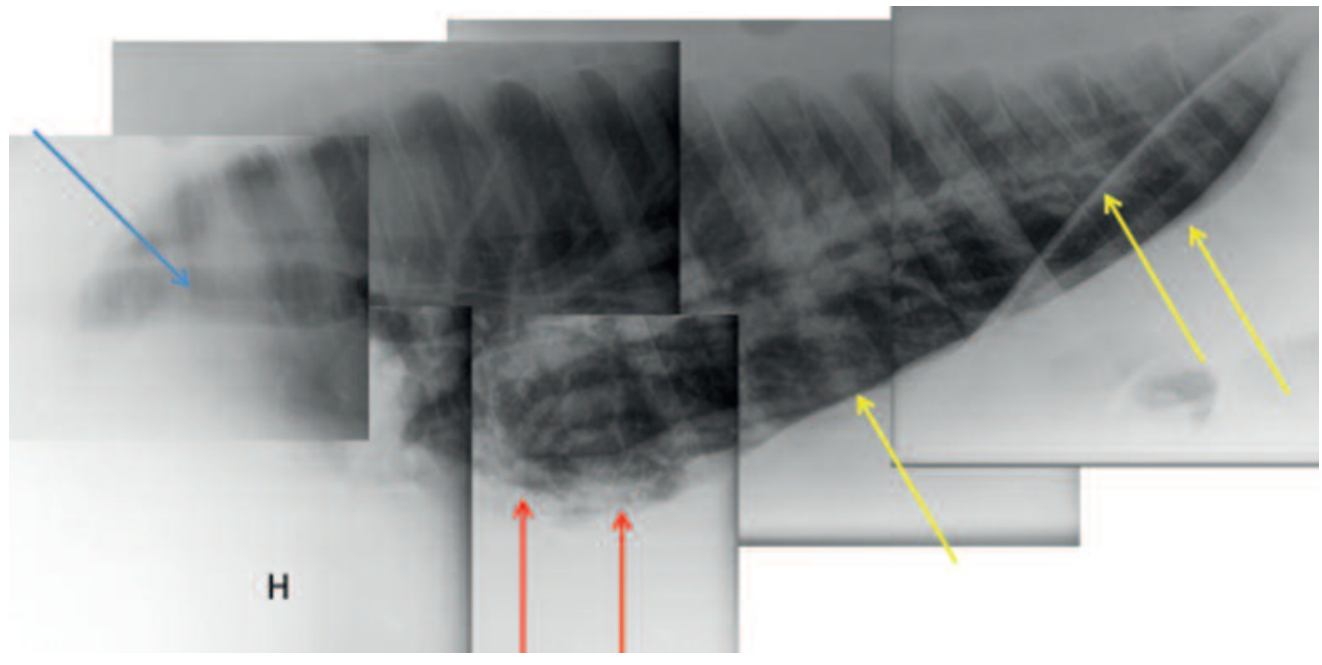

Fig. 2 X-rays of a 15-year old Belgian draft horse mare with lymphoma; to give a clear view the figure is a composition of six $X$ rays (SD views) showing an increased density in the ventral part of the thoracic cavity; the silhouette of the heart $(\mathrm{H})$ is not visible due to fluid accumulation (most likely) or a mass; blue arrow = trachea, red arrows = upper limit of the fluid accumulation, yellow arrows = diaphragm. 
ted, as well as a mild normocytic normochromic anaemia (0.27 L/L; reference range $0.30-0.43 \mathrm{~L} / \mathrm{L}$; Table 1). A blood smear showed atypical lymphocytes and monocytosis (Figures $4 \mathrm{a}$ and $4 \mathrm{~b}$ ). These results are suggestive of leukaemic lymphoma.

\section{Fine needle aspiration (FNA)}

Cytological evaluation of smears obtained by fine needle aspiration from the right superficial cervical lymph node stained with May Grünwald Giemsa showed many small lymphocytes, without any characteristic features of malignancy.

\section{Pleural fluid analysis}

Thoracocentesis was carried out under ultrasound guidance. Approximately 15 litres of slightly turbid, foamy, yellow to orange, pleural fluid was released. The fluid had a total nucleated cell count of $21 \times 10^{9} / \mathrm{L}$ (reference $<10 \times 10^{9} / \mathrm{L}$ ); total protein was $72 \mathrm{~g} / \mathrm{L}$ (reference $<25 \mathrm{~g} / \mathrm{L}$ ). Cytology showed many small lymphocytes, some macrophages, neutrophilic granulocytes and occasional lymphoblasts and active mesothelial cells. The culture was negative for bacteria, but species of the yeast Debaryomyces were identified.

\section{Outcome}

Based on the clinical findings and the ancillary diagnostic test results multicentric lymphoma with secondary leukaemia due to bone marrow infiltration was strongly suspected in this case. Considering the severity of the clinical signs and the grave prognosis, the horse was euthanized after consultation with the owner.

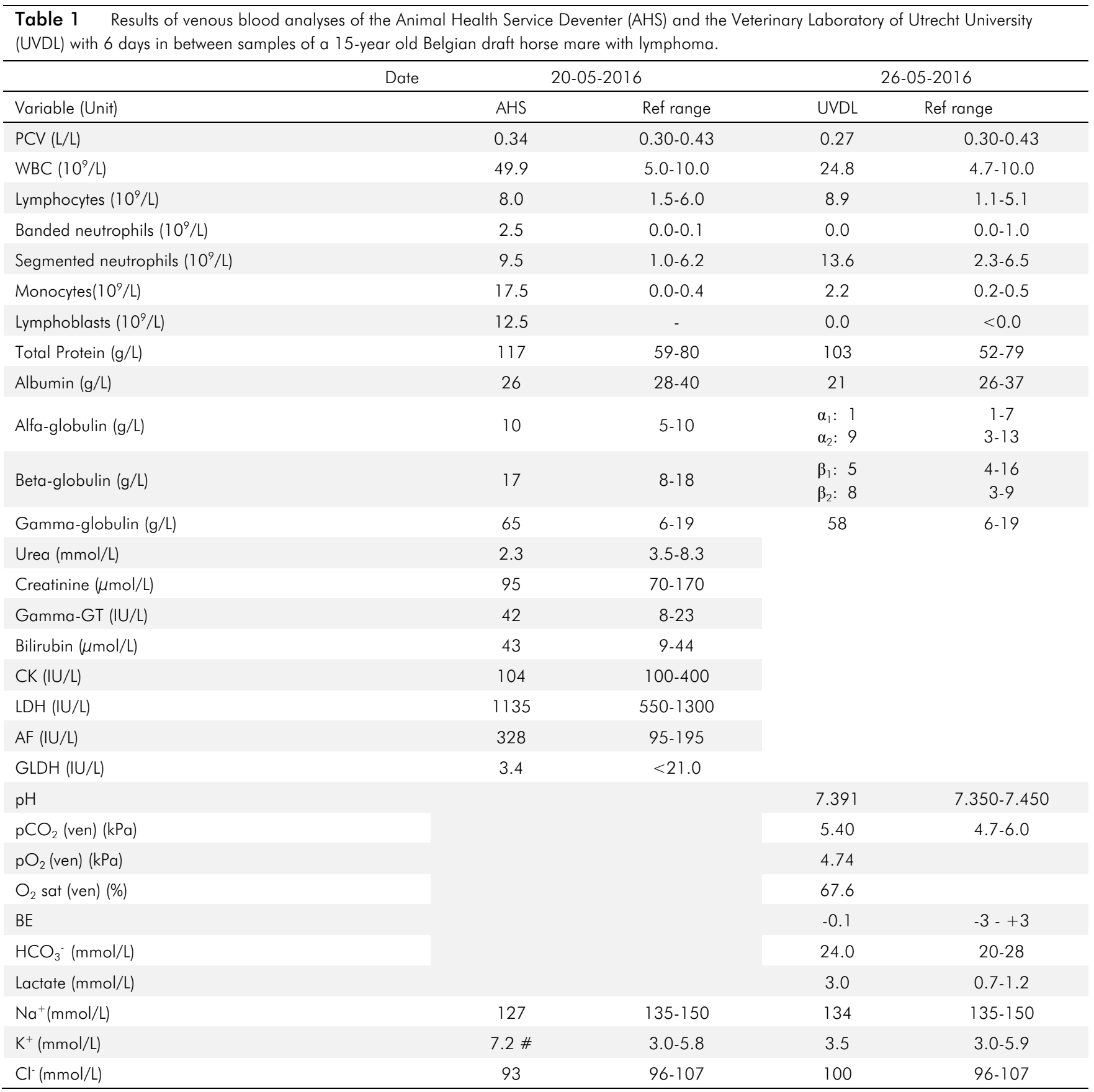




\section{Post mortem examination}

\section{Macroscopic evaluation}

The thoracic cavities contained a large amount of yelloworange clear fluid whilst in the abdominal cavity it was mildly increased. Many irregular yellow-pink nodular masses variable in size from $1 \mathrm{~mm}$ diameter to $60 \times 25 \times 5 \mathrm{~cm}$ in size were found in the subcutis and the muscles and around blood vessels in the head and neck region and the caudal vena cava, around the base of the heart, alongside the larynx and the oesophagus, on the pleura, the peritoneum and the pericardium, and within the mesentery (Figures 5 and 6). Several veins in the mesentery and the pericardium were congested.

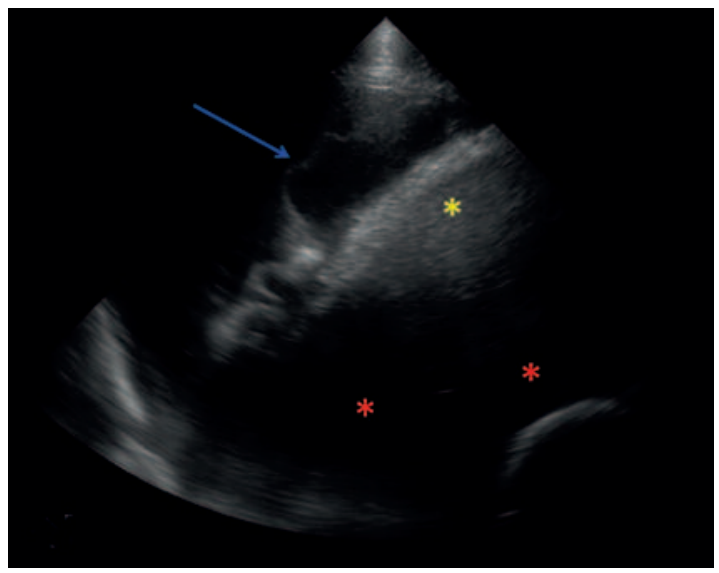

Fig. 3 Ultrasound taken below the level of the shoulder joint, in the 7th inter costal space of the left side of the thorax of a 15-year old Belgian draft horse mare with lymphoma; yellow star $=$ consolidated lung tissue, red stars $=$ free anechoic fluid, blue arrow $=$ pericardial diaphragmatic ligament. a

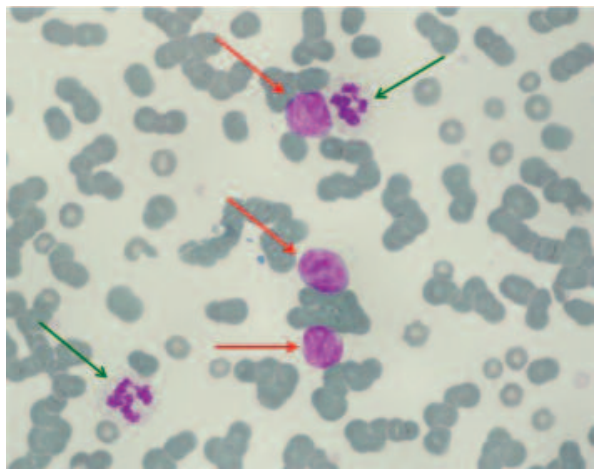

b

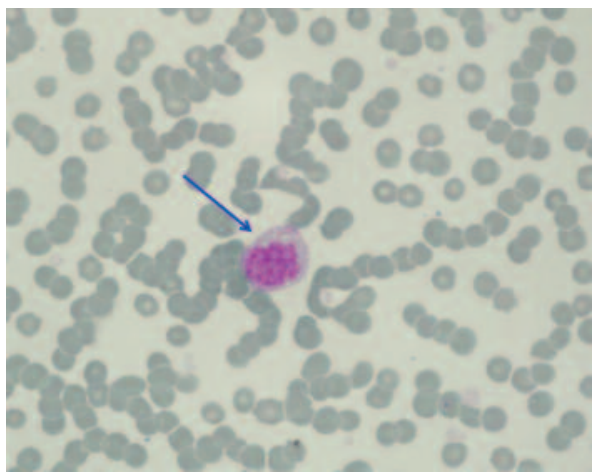

Fig. 4a and 4b Blood smears of a 15-year old Belgian draft horse mare with lymphoma showing atypical lymphocytes, characterised by mildly increased size and an amount of basophilic cytoplasm (red arrows), segmented neutrophils (green arrows) and monocyte (blue arrow) (May Grünwald-Giemsa; $1000 \times$ ).

\section{Microscopic evaluation}

All the masses demonstrated dense sheets of infiltrating round cells composed of larger neoplastic round cells consistent with B-lymphocytes, admixed with lesser numbers of normal small lymphocytes. The neoplastic cells were supported by small amounts of thin fibrovascular stroma. They had moderate to large, round to oval, occasionally indented nuclei, sometimes including large nuclei more than twice the diame-

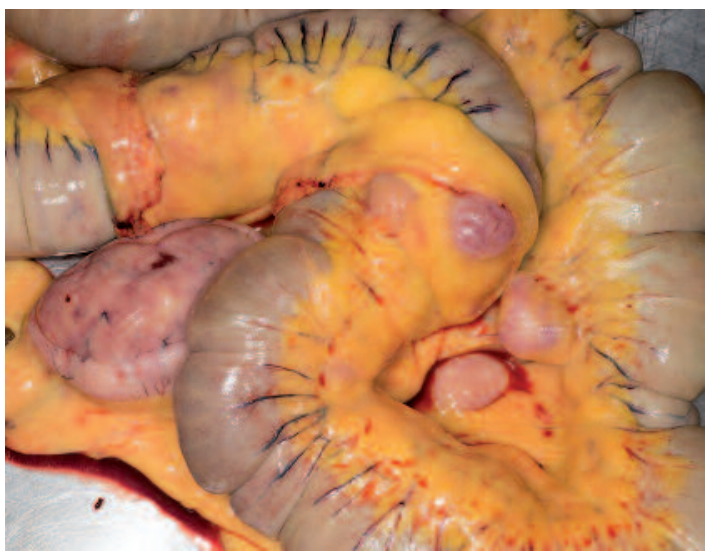

Fig. 5 Several firm pale to pink, more or less irregular oval masses, are present in the mesocolon of a 15-year old Belgian draft horse mare with lymphoma; the veins from the colon wall show congestion.

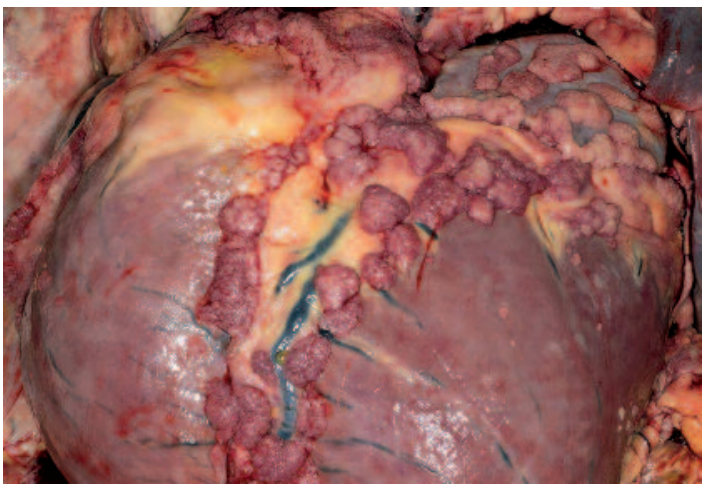

Fig. 6 Around the base of the heart and along the paraconal interventricular groove many small nodules are visible in a 15 -year old Belgian draft horse mare with lymphoma; on histology neoplastic round cells were infiltrating the myocardium.

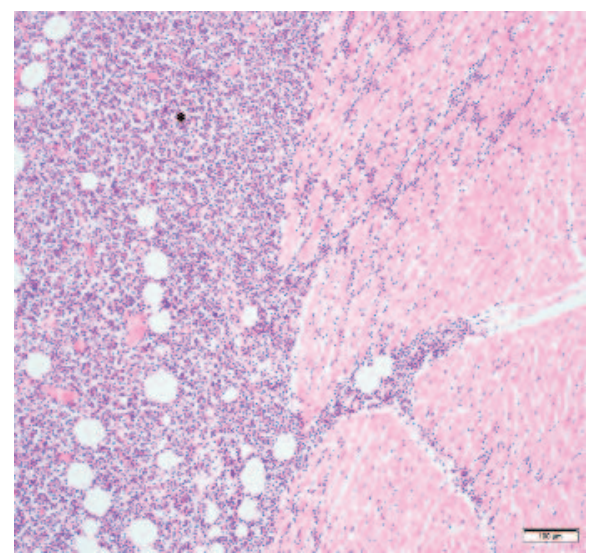

Fig. 7 Expansion of the epicardium (asterisk) and multifocal myocardial infiltration by neoplastic round cells in a 15-year old Belgian draft horse mare with lymphoma (Haematoxilin and Eosin stain, bar $=100 \mu \mathrm{m})$ 
ter of an erythrocyte and coarsely stippled chromatin. Mitotic figures averaged approximately 2 per high power field (Figure 7). No obvious necrosis, haemorrhage or vascular infiltration was seen. The oral mucosa presented a multifocal chronic mild lymphoplasmacytic granulomatous stomatitis which consisted of submucosal infiltration of small to moderate number of lymphocytes, plasma cells, some macrophage, a few neutrophils and multinucleated giant cells and mild sub-epithelial oedema. The overlying epithelium showed mild hyperplasia with multifocal mild intracellular oedema and multifocal mild neutrophilic and lymphocytic transmigration. The conjunctivae and vulvar mucosa showed mild multifocal lymphoplasmacytic inflammation.

\section{Additional immunostaining}

Immunohistochemistry was performed on sections from masses within the pericardium and neck region. CD-3 antibodies are markers for T-lymphocytes, PAX5 and CD-79-alfa for Blymphocytes. The smaller (normal) lymphocytes were CD-3 positive T-cells. The neoplastic cells were negative to CD-3, PAX5 and CD-79-alpha. These results are diagnostic for Tcell rich B-cell lymphoma.

\section{Discussion}

This mare was presented with an advanced stage of multicentric lymphoma. Multicentric lymphoma is the most common form in horses, accounting for approximately $40 \%$ of lymphoma cases (Durham et al. 2013, Ness 2016, Taintor and Schleis 2011). Multicentric lymphoma is characterised by widespread involvement of peripheral lymph nodes and a variety of abdominal, thoracic and other organs (Taintor and Schleis 2011). Dissemination most likely occurs through the lymphatic circulation. In this case many organs were affected including the lymph nodes, pleura, pericardium, mediastinum, peritoneum, mesentery, intestines, subcutis, muscles, the vascular system, mesentery and the larynx and pharynx. The lungs, spleen and liver were not involved in the disease.

The clinical signs presented in the mare were likely caused by the lymphoma masses and by the associated paraneoplastic syndromes. The lymphadenopathy and pleural effusion leading to increased heart rate and respiratory rate were probably caused directly by neoplastic masses. Stomatitis or oral ulcers have been described as a paraneoplastic condition in horses with leukaemia (Meyer et al. 2006, Boudreaux et al. 1984). This might have caused the inflammatory changes in the mucous membranes and the ptyalism in the present case. The mare in this case showed signs of cancer cachexia, which is one of the most frequently reported paraneoplastic syndromes in human medicine and is indicative of a poor prognosis (Axiak and Johnson 2011 , Muñoz et al. 2009). The anorexia and severe weight loss could be attributed to an increased resting energy use together with cancer associated inflammation. Inflammatory mediators can up-regulate pituitary proopiomelanocortin expression, inducing increased amounts of melanocortins. This mechanism can cause anorexia (Axiak and Johnson 2011). Pyrexia caused by paraneoplastic inflammatory mediators such as interleukin-1 (IL-1), IL-6, TNF $\alpha$ and interferons is often encountered in lymphoma cases (Axiak and Johnson 2011) and this was present in the current case.

In literature both erythrocytosis and anaemia are described in cases of lymphoma, although anaemia occurs far more commonly (Knottenbelt et al. 2015, Muñoz et al. 2009). The anaemia is attributed to the destruction of antibody coated erythrocytes, or to inadequate production of erythrocytes because of myelophthisis or chronic inflammation, or to blood loss through intestinal inflammation (Knottenbelt et al. 2015, Muñoz et al. 2009, Taintor and Schleis 2011).

The lymphocyte count is rarely increased in horses with lymphoma, but when affected horses are leukaemic atypical or abnormal immature lymphocytes may be identified in peripheral blood (Ness 2016, Taintor and Schleis 2011 ), together with neoplastic involvement of the bone marrow (Ness 2016). In the present case both immature and mature lymphocytes were found in the peripheral circulation indicative of a combined acute and chronic stage of lymphocytic leukaemia or a leukaemic phase from advanced lymphoma (Muñoz et al. 2009).

The increased numbers of monocytes found in the first blood samples could be indicative of an inflammatory response, myelomonocytic leukaemia or misinterpretation of the white blood cell differentiation by the laboratory analyser. It is often difficult to make a differentiation between primary and secondary leukaemia (Cian et al. 2013). Differentiation between primary lymphoma or primary leukaemia is reliant upon involvement of peripheral tissue as compared to the involvement of bone marrow. In cases of primary leukaemia the peripheral tissues have lesser involvement. (Muñoz et al. 2009). Combining the clinical presentation of the horse together with the histopathology results multicentric lymphoma was the primary diagnosis. Regrettably the bone marrow was not examined in the present case and therefore no final conclusion about the specific form of leukaemia was possible.

The difference in WBC count between laboratory assays taken 6 days apart has been described earlier by de Bruijn et al (2001). In the latter paper the difference was attributed to administration of a large dose of corticosteroids $10.2 \mathrm{mg} / \mathrm{kg}$ dexamethasone). In the present case only a single low dose of corticosteroids was administered between the blood samples, however this might not be enough to cause these major differences $\left(49.9 \times 10^{9} / \mathrm{L}\right.$ vs $\left.24.8 \times 10^{9} / \mathrm{L}\right)$. Another possible explanation for the wide difference could be that the horse might have been suffering from an acute leukaemic 'blast' crisis when the first sample was taken, meaning that more than $20 \%$ of the blood cells consist of the blast cell type. A third probably less likely explanation might be differences in the laboratory analysis since the two samples were analysed in different laboratories. The neutrophilia was probably due to tumour necrosis (Meyer et al. 2006, Taintor and Schleis 2011).

In both blood samples a monoclonal gammopathy was detected. In horses this is encountered in some lymphoma and myeloma cases (Muñoz et al. 2009, Pusterla et al. 2004). The neoplastic plasma cells (B-lymphocytes) produce a single immunoglobulin class, exceeding normal polyclonal immunoglobulins and resulting in a monoclonal gammopathy. (Axiak and Johnson 2011, Muñoz et al. 2009 Pusterla et al. 2004). Immuno-phenotyping is used to determine the original cell 
type of the tumour. Both B-cell and T-cell lymphoma occur in low-grade and high-grade forms. There is conflicting evidence on the frequency of T-cell and B-cell types in lymphoproliferative neoplasia in horses (de Bruijn et al. 2007, Meyer et al. 2006, Westerman et al. 2014). The lack of a clear staining with B-lymphocyte markers in the present case could be due to lack of reactivity of the tissue due to lack of expression of specific molecules by the tumour cells. This phenomenon has been reported before in B-cell lymphomas (Meyer et al. 2006). The phenotype of the neoplastic cells confirmed a Blymphocytic origin, therefor a T-cell-rich-B-cell-lymphoma was suggestive in the present case. This is a mixed cell type lymphoma characterised by a minor population of clonal Bcells distributed in a background of preponderant polyclonal T-lymphocytes (Cian et al. 2013, Meyer et al. 2006).

The significance of the Debaryomyces spp. found in the pleural fluid is not clear, but this yeast is considered to be nonpathogenic, and is used in the food industry (Brever and Harms 2006, Prista et al. 2016). In the present case most likely it was an incidental contaminant.

A definite diagnosis in lymphoma cases based on pleural fluid cytology and abdominal fluid cytology is often not possible since most lymphomas are not exfoliative (Schmitz and Grabner 2008). Additionally, fine needle aspiration biopsies are often not conclusive either (Muñoz et al. 2009). To make a definite diagnosis in the present case histopathologic evaluation of bone marrow aspirates and hollow needle biopsies (Tru$\left.\mathrm{Cut}^{\circledR}\right)$ of one of the masses could have been used. Thymidine kinase (TK) is a cellular enzyme involved in DNA synthesis and therefore increases when cells are in replicative stages. A study in horses showed that increases in TK type 1 is indicative of hematopoietic neoplasia and could be used as a tumour biomarker (Larsdotter et al. 2015). However, it has a low sensitivity (74\%) and specificity (14\%) at the suggested cut-off value of 2.2 U/L (Larsdotter et al. 2015) and therefore this test is not suitable as a single marker for lymphoma. It is currently only available in some specialised laboratories. Cytochemistry can be used to classify leukaemia into the myeloid lineage, lymphoid lineage or the monocytic lineage (Muñoz et al. 2009).

Several palliative treatment regimens using chemotherapeutic protocols have been described, but no reported treatment will stop the progression of the disease and the prognosis remains grave (Muñoz et al. 2009), therefor treatment was not attempted in the present case.

In conclusion, the present case was an advanced case of equine multicentric T-cell-rich B-cell- lymphoma with extensive metastasis and was presented during a leukaemic phase.

\section{Acknowledgment}

The authors thank the owner for permission to perform the post mortem examination of the horse for this case study.

\section{Abbreviations}

WBC: White blood cell count

FNA: Fine Needle Aspiration

\section{References}

Axiak S., Johnson P. J. (2012) Paraneoplastic manifestations of cancer in horses. Equine Vet. Educ. 24, 367-376

Boudreaux M. K. Blue J. T., Durham S. K., Vivrette S. L. (1984) Intravascular leukostasismin a horse with myelomonocytic leukemia. Vet. Pathol. 21, 544-546

Brever U., Harms H. (2006) Debaryomyces hansenii - an extremophilic yeast with biotechnological potential. Yeast 23, 415-437

de Bruijn C. M., van den Ingh T. S. G. A. M., Teske E., Rutten V. P. M. G., Sloet van Oldruitenborgh-Oosterbaan M. M. (2001) Maligne lymfoom bij het paard: een atypische klinische manifestatie. Tijdschr. Diergeneeskd. 126, 744-748

de Bruiin C. M., Veenman J. N., Rutten V. P. M. G., Teske E., van Nieuwstadt R. A., van den Ingh T. S. G. A. M. (2007) Clinical, histopathological and immunophenotypical findings in five horses with cutaneous malignant lymphoma. Research in Vet. Science 83, 63-72

Cian F., Tyner G., Martine V. Comazzi S., Archer J. (2013) Leukemic small cell lymphoma or chronic lymphocytic leukemia in a horse. Vet. Clin. Pathol. 42, 301-306

Durham A. C., Pillitteri C. A. San Myint M., Valli V. E. (2013) Two hundred three cases of equine lymphoma classified according to the World Health Organisation classification criteria. Vet. Pathol. 50, 86-93

Henneke D. R., Potter G. D., Krieder J. L., Yeates B. F. (1983). relationship between condition score, physical measurements and body fat percentages in mares. Equine Vet. J. 15, 371-372

Janvier V., Evrard L., Cerri S., Gougnard A., Busoni V. (2016) Ultrasonographic findings in 13 horses with lymphoma. Vet. Radiol. Ultrasound 57, 65-74

Knottenbelt D., Patterson-Kane J. C., Snalune K. L. (2015) Clinical Equine Oncology. 1st ed Elsevier, 342-356

Larsdotter S., Nostell K., von Euler H. (2015). Serum thymidine kinase activity in clinically healthy and diseased horses: a potential marker for lymphoma. Vet. J. 205, 313-316

Meyer J., DeLay J., Bienzle D. (2006) Clinical, Laboratory, and Histopathologic features of Equine Lymphoma. Vet. Pathol. 43, 914-924

Muñoz A., Riber C., Trigo P., Castejón F. (2009) Hematopoietic Neoplasias in Horses: Myeloproliferative and Lymphoproliferative Disorders. J. Equine Sci 20, 59-72

Ness S. L. (2016) in Equine Clinical Immunology. 1st ed, Wiley Blakwell, 181-191

Prista C., Michán C. Miranda I. M., Ramos J. (2016) The halotolerant Debaryomyces hansenii, the Cinderella of non-conventional yeasts. Yeast Epub doi: 10.1002/yea.3177

Pusterla N., Stacy B. A., Vernau W., de Cock H. E. V., Magdesian K. G. (2004) Immunoglobulin A monoclonal gammopathy in two horses with multiple myeloma. Vet. Rec. 155, 19-23

Schmitz R. R., Grabner A. (2008)Differenzialdiagnose innere Tumore beim Pferd mit besonderen Berücksichtigung der Zytologie von Körperhöhlenpunktaten. Pferdeheilkunde 24, 353-366

Schwarz B., Gruber A., Benetka V., Rütgen B., Schwendenwein I., Leidinger E., van den Hoven R. (2012). Concurrent T cell leukaemia and equine multinodular pulmonary fibrosis in a Hanoverian Warmblood mare. Equine Vet. Educ. 24, 187-192

Taintor J. S., Schleis S. (2011) Equine lymphoma. Equine Vet. Educ. 23, 205-213

Westerman T. L., Poulsen K. P., Schlipf J. W., Valentine B. A. (2014) Neutropenic T-cell-rich B-cell lymphoma in a 14-year-old Morgan gelding. Can. Vet. J. 55, 379-382 